\title{
The effect of ivabradine on functional capacity in patients with chronic obstructive pulmonary disease
}

\author{
Authors: Kareem Mahmoud, ${ }^{\mathrm{A}}$ Hussien Heshmat Kassem, ${ }^{\mathrm{B}}$ Essam Baligh, ${ }^{\mathrm{C}}$ Usama ElGameel, ${ }^{\mathrm{D}}$ Yosri Akl ${ }^{\mathrm{E}}$ \\ and Hossam Kandil ${ }^{C}$
}

Increased sympathetic tone and use of bronchodilators increase heart rate and this may worsen functional capacity in patients with chronic obstructive pulmonary disease (COPD). The aim of this study was to look at the short-term effect of the heart rate lowering drug ivabradine on clinical status in COPD patients. We randomised 80 COPD patients with sinus heart rate $\geq 90 \mathrm{bpm}$ into either taking ivabradine $7.5 \mathrm{mg}$ twice per day or placebo for two weeks. We assessed all patients using the modified Borg scale and 6-minute walk test at baseline and then again 2 weeks after randomisation. There were no significant differences in age, sex, severity of airway obstruction (measured using forceful exhalation), severity of diastolic dysfunction or pulmonary artery systolic pressure between the two groups. The ivabradine group showed significant improvement in 6-minute walk distance (from $192.6 \pm 108.8 \mathrm{~m}$ at baseline to $285.1 \pm 88.9 \mathrm{~m}$ at the end of the study) compared with the control group (230.6 \pm 68.4 at baseline and $250.4 \pm 65.8 \mathrm{~m}$ at the end of study) $(p<0.001)$. This improvement in the drug group was associated with significant improvement of dyspnea on modified Borg scale $(p=0.007)$. Lowering heart rate with ivabradine can improve exercise capacity and functional class in COPD patients with resting heart rate $>90 \mathrm{bpm}$.

KEYWORDS: Ivabradine, COPD, Borg scale, 6MWT

\section{Introduction}

Tachycardia is a common physical finding in patients with chronic obstructive pulmonary disease (COPD). Chronic hypoxia causes norepinephrine spill, which leads to increased sympathetic tone (increased sympathetic discharge or stimulation) and acceleration of heart rate. ${ }^{1,2}$ The incidence of

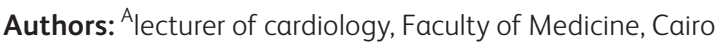
University, Cairo, Egypt; ${ }^{B}$ associate professor of cardiology, Faculty of Medicine, Cairo University, Cairo, Egypt; ' cardiology, Faculty of Medicine, Cairo University, Cairo, Egypt; Dlecturer of chest, Faculty of Medicine, Cairo University, Cairo, Egypt; Eprofessor of chest, Faculty of Medicine, Cairo University, Cairo, Egypt. sinus tachycardia and atrial arrhythmias in patients with COPD increases with frequent use of bronchodilators ( $\beta 2$-agonists, theophylline and steroids). ${ }^{1,3}$ Resting heart rate increases with increasing severity of COPD and tachycardia can increase both cardiovascular and all-cause mortality, independent of pulmonary function. ${ }^{5}$ Tachycardia can reduce the exercise tolerance in COPD patients by increasing myocardial oxygen demand and decreasing coronary perfusion time. Shortened diastole also causes incomplete relaxation between beats, resulting in an increase in diastolic pressure relative to volume. $^{6,7}$

Ivabradine selectively and specifically inhibits funny current (If), a primary sinoatrial node pacemaker current, reducing heart rate at rest and during exercise. There is no negative inotropic effect or blood pressure reduction with ivabradine compared with beta-blockers and non-dihydropyridine calcium channel blockers. ${ }^{8}$ Heart rate reduction with ivabradine has been found to decrease morbidity and mortality among patients with heart failure with reduced ejection fraction. ${ }^{9}$ The purpose of this trial was to study the effect of heart rate reduction with ivabradine on the symptoms and functional capacity in COPD patients.

\section{Patients and methods}

\section{Patients}

We enrolled COPD patients with sinus rhythm and resting heart rate of more than $90 \mathrm{bpm}$ that were presented to the chest department at Kasr ElAini Hospital from May 2012 to April 2014. Before randomisation, all patients were stabilised with inhaled bronchodilators \pm steroids for COPD exacerbation and diuretics for right-sided heart failure.

Patients were excluded for the following reasons:

$>$ coronary artery disease evidenced by history of angina or myocardial infarction, electrocardiogram suggestive of coronary artery disease or echocardiography showing resting regional wall motion abnormalities

$>$ uncontrolled hypertension (systolic blood pressure $\geq 140 \mathrm{mmHg}$ and diastolic blood pressure $\geq 90 \mathrm{mmHg}$ )

$>$ left ventricular systolic dysfunction on echocardiography (left ventricular ejection fraction $<50 \%$ )

$>$ left ventricular hypertrophy on echocardiography (wall thickness $>1.1 \mathrm{~cm}$ ) 
significant valvular heart disease

$>$ poor echocardiographic window

$>$ inability to sign informed consent.

The study was approved by the ethics committee in our institution. All patients provided signed informed consent.

\section{Methods}

\section{Baseline visit (day 0)}

During the baseline visit, all patients were randomised into two groups:

1 patients who continued on standard COPD management (control group)

2 patients who continued on standard COPD management in addition to ivabradine $7.5 \mathrm{mg}$ twice daily (drug group).

We evaluated all of the enrolled patients using the following methods:

$>$ History and clinical examination including subjective assessment of the patient's dyspnea using a modified Borg scale where $0=$ no dyspnea, 1 = very light dyspnea, $2=$ light dyspnea, $3=$ moderate dyspnea, $5=$ intense dyspnea, $7=$ very intense dyspnea, $9=$ very, very intense dyspnea and $10=$ maximum dyspnea. ${ }^{10}$

$>$ Electrocardiogram for chamber enlargement, rhythm and rate.

> Chest X-ray for evidence of chamber enlargement or pulmonary abnormalities (consolidation, fibrosis, collapse, etc).

> Pulmonary function tests: ${ }^{11}$ forced vital capacity (FVC), forced expiratory volume in the first second of the forceful exhalation (FEV1) and FEV1/FVC ratio.

$>6$-minute walk test ${ }^{12}$ performed in an enclosed corridor (crash trolley with available oxygen supply nearby) - the patient was asked to walk as far as possible in 6 minutes. The patient was permitted to slow down, to stop, and to rest as necessary then resume walking as soon as they were able. Then, the distance they had walked was measured.

> Echocardiographic examination: $:^{13-15}$ a standard twodimensional echocardiography machine (Vivid S5, GE Healthcare, USA) was used to obtain parasternal, apical, and subcostal views of the heart in order to measure the following:

- left ventricular dimensions and ejection fraction

- right ventricular dimensions measured at the base of right ventricle, at mid-ventricle and longitudinal dimension

- pulsed wave Doppler on mitral valve for evaluation of mitral inflow estimating $\mathrm{E} / \mathrm{A}$ ratio and $\mathrm{E}$ wave deceleration time

- tissue Doppler imaging for lateral mitral annulus, estimating mitral annular diastolic velocities (E' and A'), systolic velocity (S') and mitral E/E',

- left ventricular Tei index ${ }^{16}$

- tissue Doppler imaging for lateral tricuspid annulus, estimating tricuspid annular diastolic velocities (E' and A') and systolic velocity (S')

- right ventricular Tei index ${ }^{17}$

- tricuspid annular plane systolic excursion (TAPSE) by M-mode of lateral tricuspid annulus

- pulmonary artery systolic pressure (PASP).

Beta subunit of brain naturetic peptide (B-BNP).

\section{Second visit after 2 weeks (day $15 \pm 2$ days)}

All measures done during baseline visit were repeated during the second visit.

\section{Statistical analysis}

Continuous variables were presented as mean \pm 1 standard deviation (SD) and categorical variables as numbers and percentages if normally distributed. Comparisons between the items were made by t-test, ANOVA and Wilcoxon rank-sum tests for continues variables and chi-square and fisher's exact tests for categorical variables.

\section{Results}

We screened 140 COPD patients presenting to either the chest department or chest outpatient clinic (Kasr AlAiny Hospital). We excluded 60 patients as they met the exclusion criteria. We randomised 80 patients into the drug group (40 patients) and control group (40 patients). Table 1 shows baseline characteristics of both groups with no statistical significant differences regarding clinical, laboratory, echocardiographic and pulmonary function data between both groups. The control group were able to travel further during the 6-minute walk distance (230.6 \pm 68.4 meters) compared with drug group (192.6 \pm 108.8 meters) but this trend was not significant $(\mathrm{p}=0.07)$. Fig 1 shows the difference between both groups according to the modified Borg scale.

We reassessed the patients after receiving either ivabradine $7.5 \mathrm{mg}$ twice daily or a placebo for 14 days. The drug group showed a significant reduction in heart rate from $98.2 \pm 7.2 \mathrm{bpm}$ to $72.8 \pm 6.1 \mathrm{bpm}(\mathrm{p}<0.001)$ with no significant change in heart rate in the control group. This heart rate reduction was associated with improvement in modified Borg scale score (Fig 2) and 6-minute walk distance (Fig 3) compared with the control group. No statistically significant difference was found between both groups regarding echocardiographic parameters or FEV1. The drug group showed mild adverse effects in the form of blurred vision (10\%), sinus bradycardia 50-60 bpm $(7.5 \%)$ and headache $(5 \%)$.

\section{Discussion}

Tachycardia is a common finding in COPD patients because of the frequent use of bronchodilators and increased sympathetic tone. ${ }^{1,4}$ Tachycardia can aggravate COPD disease state, possibly by worsening the diastolic function that is already impaired in COPD. In this study, we tested the effect of reducing heart rate with ivabradine on the functional capacity in patients with COPD.

Most of enrolled patients were middle-aged (50-60 years) male smokers with no difference between drug and control groups regarding age, sex, smoking, body mass index, diabetes mellitus or hypertension. Their main symptoms were dyspnea and exercise intolerance as a result of occlusive airway disease; there was no statistical significant difference between the control and drug groups regarding degree of dyspnea as assessed by modified Borg scale $(\mathrm{p}=0.23)$. Both groups showed relatively rapid heart rate $(99.7 \pm 12.0 \mathrm{bpm}$ versus $98.3 \pm 7.4 \mathrm{bpm}$; $\mathrm{p}=0.53$ ). Several factors are responsible for rapid heart rate 


\begin{tabular}{|c|c|c|c|}
\hline & Control $(n=40)$ & Drug $(n=40)$ & $\mathrm{p}$-value \\
\hline Age (years) & $60.3 \pm 8.1$ & $57.4 \pm 8.4$ & 0.12 \\
\hline Male gender ( $\mathrm{n}$ ) & $40(100 \%)$ & $38(95 \%)$ & 0.49 \\
\hline Smoking (n) & $38(95 \%)$ & $36(90 \%)$ & 0.68 \\
\hline HTN (n) & $4(10 \%)$ & $5(12.5 \%)$ & 1.00 \\
\hline $\mathrm{DM}(\mathrm{n})$ & $5(12.5 \%)$ & $4(10 \%)$ & 1.00 \\
\hline RSHF (n) & $8(20 \%)$ & $13(32.5 \%)$ & 0.20 \\
\hline $\begin{array}{l}\text { Modified Borg } \\
\text { scale }\end{array}$ & $4.9 \pm 1.4$ & $5.3 \pm 1.3$ & 0.23 \\
\hline BMI $\left(\mathrm{Kg} / \mathrm{m}^{2}\right)$ & $25.2 \pm 5.0$ & $25.5 \pm 3.8$ & 0.79 \\
\hline $\mathrm{SBP}(\mathrm{mmHg})$ & $122.4 \pm 10.5$ & $125.9 \pm 9.9$ & 0.13 \\
\hline $\mathrm{DBP}(\mathrm{mmHg})$ & $79.4 \pm 11.2$ & $79.5 \pm 7.8$ & 0.95 \\
\hline HR (bpm) & $99.7 \pm 12.0$ & $98.3 \pm 7.4$ & 0.53 \\
\hline $\mathrm{BNP}(\mathrm{ph} / \mathrm{mL})$ & $40.6 \pm 22.1$ & $42.1 \pm 23.3$ & 0.76 \\
\hline 6MWD (m) & $230.6 \pm 68.4$ & $192.6 \pm 108.8$ & 0.07 \\
\hline $\operatorname{LVEF}(\%)$ & $69.1 \pm 8.2$ & $69.0 \pm 8.9$ & 0.99 \\
\hline $\mathrm{LA}(\mathrm{cm})$ & $3.2 \pm 0.6$ & $3.1 \pm 0.8$ & 0.79 \\
\hline Mitral E/A & $0.76 \pm 0.19$ & $0.88 \pm 0.28$ & 0.03 \\
\hline EDT (msec) & $217.8 \pm 72.8$ & $223.7 \pm 68.9$ & 0.71 \\
\hline$E^{\prime}(\mathrm{cm} / \mathrm{sec})$ & $10.3 \pm 3.7$ & $11.1 \pm 3.4$ & 0.35 \\
\hline$A^{\prime}(\mathrm{cm} / \mathrm{sec})$ & $13.2 \pm 3.6$ & $14.2 \pm 3.4$ & 0.22 \\
\hline $\mathrm{S}^{\prime}(\mathrm{cm} / \mathrm{sec})$ & $11.8 \pm 3.2$ & $13.0 \pm 3.8$ & 0.16 \\
\hline$E / E^{\prime}$ & $6.3 \pm 3.6$ & $6.3 \pm 3.4$ & 0.95 \\
\hline LV MPI & $0.48 \pm 0.19$ & $0.49 \pm 0.15$ & 0.76 \\
\hline PASP $(\mathrm{mmHg})$ & $40.0 \pm 15.9$ & $42.0 \pm 12.6$ & 0.72 \\
\hline FEV1 (L) & $1.37 \pm 0.65$ & $1.23 \pm 0.50$ & 0.27 \\
\hline FEV1 (\% predicted) & $41.15 \pm 19.97$ & $36.90 \pm 15.11$ & 0.29 \\
\hline
\end{tabular}

$6 M W D=6$-minute walk distance; $A^{\prime}=A^{\prime}$ wave velocity at lateral mitral annulus; $\mathrm{BNP}=$ brain naturetic peptide; $\mathrm{BMI}=$ body mass index; $\mathrm{DBP}=$ diastolic blood pressure; $\mathrm{DM}=$ diabetes mellitus; $\mathrm{E}^{\prime}=\mathrm{E}^{\prime}$ wave velocity at lateral mitral annulus; $E D T=E$ wave deceleration time; $F E V 1=$ forced expiratory volume in first second; $H R=$ heart rate; $H T N$ = hypertension; $L A=$ left atrium; $L V E F=$ left ventricular ejection fraction; $L V$ MPI $=$ left ventricular myocardial performance index; Mitral $E / A=$ mitral $E / A$ ratio; $P A S P=$ pulmonary artery systolic pressure; RSHF = right-sided heart failure; $S^{\prime}=S^{\prime}$ wave velocity at lateral mitral annulus; $\mathrm{SBP}=$ systolic blood pressure.

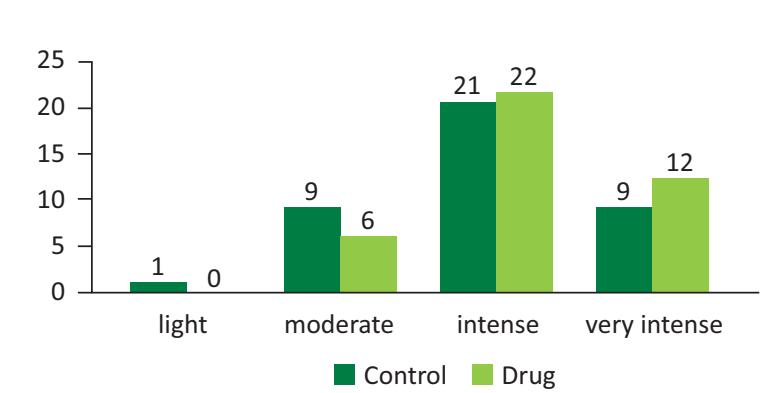

Fig 1. Baseline modified Borg scale in control and drug groups $(p=0.24)$.

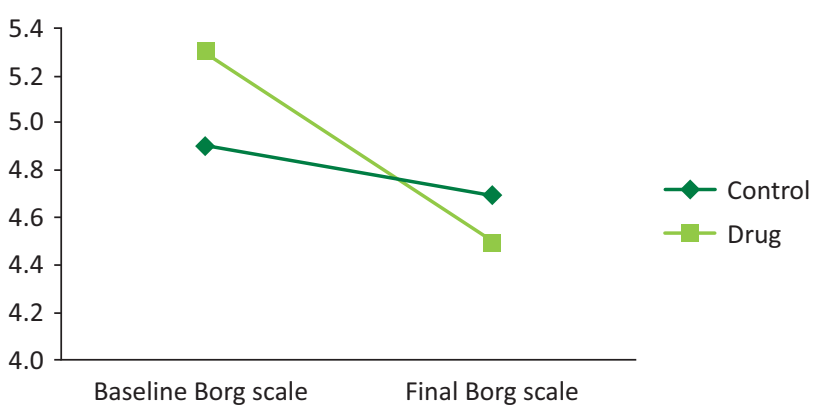

Fig 2. Change in modified Borg scale from visit 1 to visit $2(p=0.007)$.

in COPD patients. Hypoxia causes sympathetic stimulation through increasing the level of catecholamine release. Also, frequent use of bronchodilators, including beta-adrenergic agonists, methylxanthines and inhaled steroids could accelerate heart rate.

6-minute walk distance was found to be longer among the control group $(230.6 \pm 68.4 \mathrm{~m})$ compared with the drug group (192.6 $\pm 108.8 \mathrm{~m})$. However, this result was not statistically significant $(\mathrm{p}=0.07)$. We did not find statistically significant differences between the two groups regarding echocardiographic data or pulmonary functions tests. Thus, both groups seem to share similar baseline characteristics with no strong confounding variables.

Ivabradine was studied in patients with heart failure with reduced ejection fraction in the SHIFT study. ${ }^{18}$ The use of ivabradine was associated with a significant improvement in New York Heart Association class, a reduction in admission due to all-cause and any cardiovascular disease and reduction in mortality due to all causes and any cardiovascular disease. ${ }^{18}$

In our study, the use of ivabradine was associated with a reduction in heart rate and significant improvement of modified Borg scale and 6-minute walk distance. In another study, Pal et al ${ }^{19}$ found that heart rate reduction with ivabradine was not associated with an improvement in exercise capacity. That study included different categories of patients; namely heart failure with preserved ejection fraction $(\mathrm{HFpEF})$ and asymptomatic hypertensives. Patients were also considerably older (74.6 \pm 5.9 years and $66.9 \pm 5.2$ years for $\mathrm{HFpEF}$ and

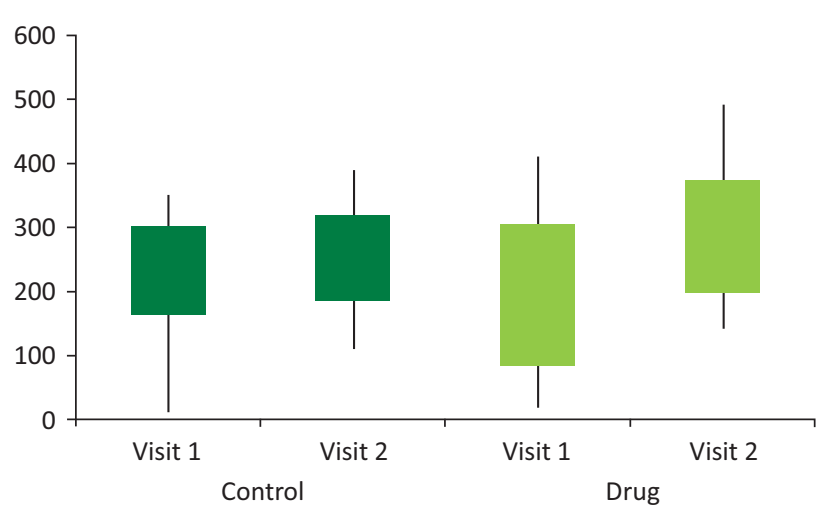

Fig 3. Change in 6-minute walk distance (in metres) from visit 1 to visit $2(p<0.001)$. 
asymptomatic hypertensives, respectively) compared with $60.3 \pm 8.1$ years in our study. Moreover, a resting heart rate more than $90 \mathrm{bpm}$ was an inclusion criterion in our study, while in the study by Pal et al, resting heart rate was significantly lower $(75 \pm 12 \mathrm{bpm}$ and $78 \pm 14 \mathrm{bpm}$ for HFpEF patients and asymptomatic hypertensives, respectively). In our study, ivabradine reduced heart rate from $98.2 \pm 7.2 \mathrm{bpm}$ to $72.8 \pm 6.1$ bpm, whereas it reduced the heart rate from 77 to $57 \mathrm{bpm}$ in the study from $\mathrm{Pal}$ et al. It appears that excessive heart rate reduction in HFpEF patients may be deleterious, especially in the presence of chronotropic incompetence and advanced diastolic disease because heart rate is a major determinant of cardiac output. ${ }^{20}$ In COPD patients, control of excessive tachycardia due to combined sympathetic overstimulation and frequent use of sympathomimetics may be beneficial in improving exercise capacity.

We did not find any significant difference between both groups regarding FEV1 as ivabradine has no effect on pulmonary function. Again, we did not find a significant difference between both groups regarding the echocardiographic data of left and right ventricles despite the above mentioned significant improvement in clinical condition. This could be explained by the lack of reliability of echocardiographic diastolic measurements, including tissue Doppler imaging to predict the changes in diastolic function and pulmonary capillary wedge pressure in HFpEF in response to different loading conditions. ${ }^{21}$

It was reported that the use of ivabradine for more than 4 weeks was associated with increased incidence of atrial fibrillation. ${ }^{22}$ However, in our study, ivabradine was relatively safe with no severe adverse events. A study of the long-term effects of ivabradine is required to avoid precipitating atrial fibrillation in COPD patients, which can increase breathlessness and disability.

\section{Conclusion}

Ivabradine, with its heart rate lowering properties and its safety in patients with bronchoconstriction, could improve the clinical status and exercise capacity in COPD patients with rapid heart rate. The drug did not affect pulmonary function, mainly FEV1, and it was well-tolerated among COPD patients despite mild adverse effects that did not affect compliance in using the drug.

\section{Conflicts of interest}

All authors have no conflicts of interest.

\section{References}

1 Shih H-T, Webb CR, Conway W et al. Frequency and significance of cardiac arrhythmias in chronic obstructive lung disease. CHEST 1988;94:44-8.

2 Anand IS, Chandrashekhar Y, Ferrari R et al. Pathogenesis of congestive state in chronic obstructive pulmonary disease. Studies of body water and sodium, renal function, hemodynamics, and plasma hormones during edema and after recovery. Circulation 1992;86:12-21.
3 Bittar G, Friedman H. The arrhythmogenicity of theophylline. A multivariate analysis of clinical determinants. CHEST 1991;99:1415-20.

4 Kallergis EM, Manios EG, Kanoupakis EM et al. Acute electrophysiologic effects of inhaled salbutamol in humans. CHEST 2005;127:2057-63.

5 Jensen MT, Marott JL, Lange $\mathrm{P}$ et al. Resting heart rate is a predictor of mortality in COPD. Eur Respir J 2013;42:341-9.

6 Liu C-P, Ting C, Lawrence W et al. Diminished contractile response to increased heart rate in intact human left ventricular hypertrophy. Systolic versus diastolic determinants. Circulation 1993;88:1893-906.

7 Mulieri LA, Hasenfuss G, Leavitt B, Allen PD, Alpert N. Altered myocardial force-frequency relation in human heart failure. Circulation 1992;85:1743-50.

8 Borer JS, Fox K, Jaillon P, Lerebours G. Antianginal and antiischemic effects of ivabradine, an if inhibitor, in stable angina a randomized, double-blind, multicentered, placebo-controlled trial. Circulation 2003;107:817-23.

9 Pfeffer MA, Swedberg K, Granger CB et al. Effects of candesartan on mortality and morbidity in patients with chronic heart failure: The charm-overall programme. Lancet 2003;362:759-66.

10 Borg GAV. Psychophysical bases of perceived exertion. Med Sci Sports Exerc 1982;14:377-81.

11 Miller MR, Hankinson J, Brusasco V et al. Standardisation of spirometry. Eur Respir J 2005;26:319-38.

12 ATS Committee on Proficiency Standards for Clinical Pulmonary Function Laboratories. ATS statement: guidelines for the sixminute walk test. Am J Respir Crit Care Med 2002;166:111-7.

13 Rudski LG, Lai WW, Afilalo J et al. Guidelines for the echocardiographic assessment of the right heart in adults: a report from the American Society of Echocardiography. J Am Soc Echocardiogr 2010;23:685-713.

14 Nagueh SF, Appleton CP, Gillebert TC et al. Recommendations for the evaluation of left ventricular diastolic function by echocardiography. J Am Soc Echocardiogr 2009;22:107-33.

15 Lang RM, Bierig M, Devereux RB et al. Recommendations for chamber quantification. Eur J Echocardiogr 2006;7:79-108.

16 Tei C, Dujardin KS, Hodge DO et al. Doppler index combining systolic and diastolic myocardial performance: Clinical value in cardiac amyloidisis. J Am Coll Cardiol 1996;28:658-64.

17 Schiller NB, Kwan DM. The Tei index as an expression of right ventricular impairment and recoveryinvestment grade or subprime? JACC Cardiovasc Imaging 2009;2:150-2.

18 Swedberg K, Komajda M, Böhm M et al. Ivabradine and outcomes in chronic heart failure (shift): A randomised placebo-controlled study. Lancet. 2010;376:875-85.

19 Pal N, Sivaswamy N, Mahmod M et al. Effect of selective heart rate slowing in heart failure with preserved ejection fraction. Circulation 2015;132:1719-25.

20 Sharma K, Kass DA. Heart failure with preserved ejection fraction: Mechanisms, clinical features, and therapies. Circ Res 2014;115:79-96.

21 Bhella PS, Pacini EL, Prasad A et al. Echocardiographic indices do not reliably track changes in left-sided filling pressure in healthy subjects or patients with heart failure with preserved ejection fraction. Circ Cardiovasc Imaging 2011;4:482-9.

22 Martin RIR, Pogoryelova O, Koref MS et al. Atrial fibrillation associated with ivabradine treatment: Meta-analysis of randomised controlled trials. Heart 2014;100:1506-10.

Address for correspondence: Dr K Mahmoud, Faculty of Medicine, Cairo University, Kasr ElAiny Hospital, ElManial, Cairo 11562, Egypt.

Email: dr.kareem215@cu.edu.eg 